UCRL-JC-128675

PREPRINT

\title{
Prospects of and Requirements for Nuclear Power as a Contributor toward Managing Greenhouse Gases
}

\author{
J. A. Hassberger \\ R. N. Schock \\ T. H. Isaacs
}

This paper was prepared for submittal to the International Conference on Environment and Nuclear Energy

Washington, DC

October 27-29, 1997

October 23, 1997

This is a preprint of a paper intended for publication in a journal or proceedings. Since changes may be made before publication, this preprint is made available with the understanding that it will not be cited or reproduced without the permission of the author. 


\section{DISCLAIMER}

This document was prepared as an account of work sponsored by an agency of the United States Government. Neither the United States Government nor the University of California nor any of their employees, makes any warranty, express or implied, or assumes any legal liability or responsibility for the accuracy, completeness, or usefulness of any information, apparatus, product, or process disclosed, or represents that its use would not infringe privately owned rights. Reference herein to any specific commercial product, process, or service by trade name, trademark, manufacturer, or otherwise, does not necessarily constitute or imply its endorsement, recommendation, or favoring by the United States Government or the University of California. The views and opinions of authors expressed herein do not necessarily state or reflect those of the United States Government or the University of California, and shall not be used for advertising or product endorsement purposes. 


\title{
Prospects of and Requirements for Nuclear Power as a Contributor toward Managing Greenhouse
} Gases

\author{
J. A. Hassberger, R. N. Schock, T. H. Isaacs \\ University of California \\ Lawrence Livermore National Laboratory
}

The world's population, energy demand, and rate of carbon emissions are increasing, but the rates of increase are uncertain. Even modest growth rates present significant challenges to existing and developing technologies for reducing carbon and greenhouse gas emissions while meeting growing energy demands. Nuclear power is currently the most developed alternative to fossil fuel combustion and is one of the options for meeting these challenges. However, there remain significant technical, economic and institutional barriers inhibiting growth of nuclear capacity in the U.S. and slowing implementation worldwide. In the near-term, the major barriers to nuclear power, especially in the U.S., appear to be economic and institutional, with the risks such as safety, waste management and proliferation having reasonably acceptable limits considering the current installed capacity. Future growth of nuclear power, however, may well hinge on continuous evolutionary and perhaps revolutionary reduction of these risks such that the overall risk of nuclear power, aggregated over the entire installed capacity, remains at or below today's risks.

\section{INTRODUCTION}

Nuclear energy is one of the current contributors to, and future options for, reducing carbon and greenhouse gas emissions. As a demonstrated, safe and environmentally responsible source of electricity, nuclear power already accounts for some 140 million metric tonnes of avoided carbon annually in the United States, representing a $10 \%$ reduction in U.S. annual carbon emissions, and some 500 million tonnes annually worldwide. Nuclear plants can provide further reductions by replacing fossil fuels in electric production, and has potential for more reductions by providing process heat for industrial applications, district heating and alternative transportation fuels manufacturing.

The nation's energy demand is increasing, the world energy consumption rate is increasing even faster, and throughout the world, electricity's contribution to total energy consumption is rising. Increased demand is only part of the driver for new generating plant construction, as new plants are also needed to replace aging and outmoded plants, both nuclear and fossil-fueled. One-third of the total new domestic generating plant construction requirements projected through 2015 is for plant replacement, not for demand growth.

The world's energy future is uncertain, with significant uncertainties in growth rate, technology availability, and economics. The distributions of energy demand growth and resources are disparate: growth is more rapid among the developing countries and especially in East Asia, and demand growth does not overlap 
energy resource distribution. This leads to social disparities and the potential for mass migration and conflict, making energy security and sustainability national and international security issues. Finally, there is uncertainty about the world's resolve to effectively limit carbon and greenhouse emissions, especially in light of costs and impacts on economic growth. Without concurrent policies for emissions-free generation, or emissions based taxes on energy generation and use, carbon emissions in the U.S. and most other nations will continue to rise.

Flexibility and diversity are the keys to ensuring a responsible energy future in light of all these uncertainties. Both the nation and the world must ensure a safe, economic and reliable energy supply to meet anticipated future demands. Technology flexibility and fuel diversity is needed to guard against unforeseen shortcomings and supply disruptions. An full integrated mix of energy supply technologies can effectively maximize the benefits of each cechnology while minimizing the risks and costs of our energy supply systems as a whole.

\section{Today's Energy and Carbon Emissions Spectra}

Energy generation and use accounts for the vast bulk of carbon emissions. In the U.S. alone, the energy sector contributes some $90 \%$ of the nearly 1500 million metric tonnes carbon (MtC) emitted annually. On the whole, the transportation, industry and building (air conditioning, heat and light) sectors contribute each roughly $30 \%$ of the carbon emissions.

Much of these emissions are avoidable today, and today's carbon emissions would be $15 \%$ higher if it were not for emissions avoided through nuclear power (140 MtC/a, 10\%) and renewables (primarily hydro, $70 \mathrm{MtC} / \mathrm{a}, 5 \%$ ). Ultimately, a majority of current and future emissions could be avoided through a combination of renewable and nuclear energy sources combined with substantial shifts in infrastructure and energy transport systems, albeit on varying time frames.

Fossil electrical sources account for some $30 \%$ of current carbon emissions. In principal, most of this generation, especially that used for baseload, can be replaced with a combination of nuclear and renewable sources. This is a proven capability of nuclear power today.

Transportation energy use accounts for another $30 \%$ of current carbon emissions, with perhaps half of this from the light vehicle fleet, including passenger cars and light trucks. There are reasonable prospects that a substantial portion of the light fleet emissions can be avoided by conversion to electric vehicles and hybridelectric vehicles operating on hydrogen. Notwithstanding the need for continued development of the vehicle technologies and hydrogen infrastructures, this can be considered a current capability of nuclear as the primary electrical generator, and a potential future capability using hydrogen produced with nuclear process heat.

Some of the remaining emissions, roughly $10 \%$ of the total annual $(162 \mathrm{MrC} / \mathrm{a})$ is used for building heat and $20 \%$ ( $382 \mathrm{MtC} / \mathrm{a}$ ) is used in industry, substantially for process heat. Some fraction of these emissions could be avoided using electric heat from nuclear or renewable sources and thus considered a current capability. Both nuclear process heat and nuclear district heating has had limited demonstration internationally, and could be considered a potential capability in the U.S.

\section{The World's Energy Future}

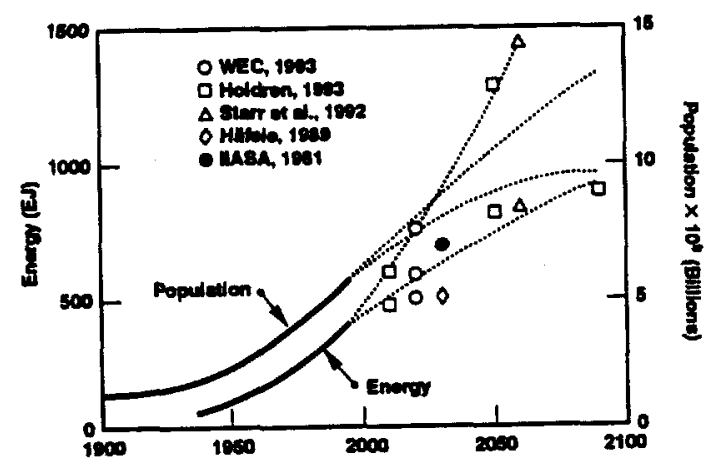

Figure 1. Actual (to 1996) and projected global population growth and energy usage'.

Historic trends in the world's population and energy use over the past century show dramatic increases in both. The beginning of the century saw a world population of only some 1.5 billion. It is now fast approaching 6 billion. As late as 1950 , the world's annual consumption of 
primary energy barely exceeded 100 exojoules (EJ, $1 \mathrm{EJ}=10^{12}$ Joules). Today, it is on the order of $400 \mathrm{EJ}$ per year. Energy use is projected to increase at an even more rapid rate. As figure 1 shows, even though various projections of population and energy growth vary, even the slowest growth scenarios offer exceptional challenges for the future. By 2020, population is expected to be at least 7.5 billion, and consume between 600 and $750 \mathrm{EJ}$ per year.

Electrical consumption is expanding much more rapidly than total energy use. The EIA projects worldwide consumption of electricity to increase over 4-fold, while total energy consumption increases "only" about 2.5 times. This trend is even more dramatic among the developing countries, where total energy consumption for the same period is expected to increase over 6fold, but electrical consumption is expected to increase over 14-fold.

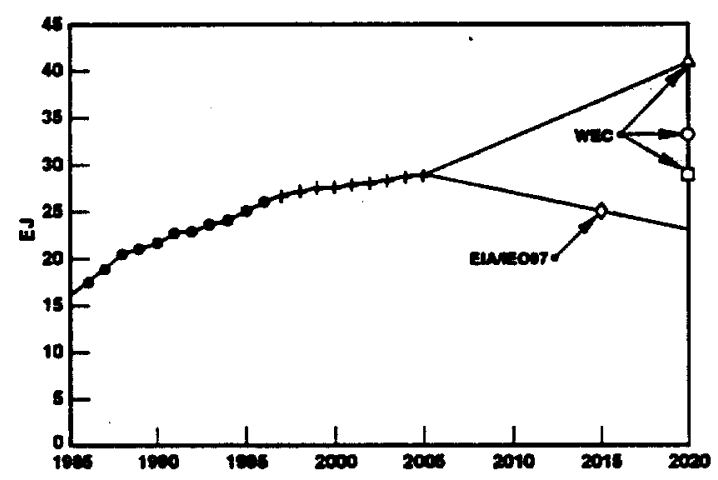

Figure 2. Actual (to 1996) and Projected global nuclear generating capacity (EJ/year) ${ }^{2}$.

Projections for the future of nuclear power vary greatly, but most show significant growth for nuclear power everywhere but in the U.S. Globally, most projections show slight to moderate growth for nuclear power, but include projected declines in U.S. domestic nuclear power generation. Figure 2 summarizes the historic capacity, capacity under construction and projections for global nuclear energy through 2020 . The only case suggesting a worldwide decline in nuclear energy is the IEO97 reference case, projecting nuclear capacity to decline from 344 gigawatts in 1995 to 332 gigawatts in 2015, primarily because nearly one-third of the present U.S. nuclear capacity ( $100 \mathrm{Gwe})$ is scheduled for retirement by $2015^{3}$. While not enough to offset planned retirements, significant increases in nuclear capacity are projected for developing countries, including an additional 31.5 gigawatts by 2015 in China, South Korea, India, and Taiwan. This area has the highest rate of growth in electricity demand in the world and is therefore in need of extensive baseload capacity additions. Current and projected regional distributions of nuclear generating capacity under this scenario are summarized on Figure 3.

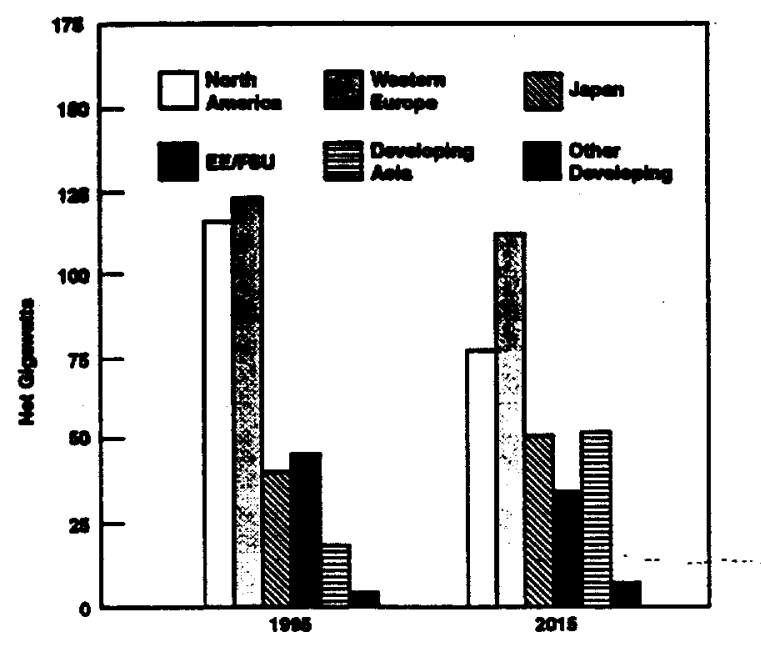

Figure 3. World nuclear energy capacity by region in 1995 and $2015^{4}$.

Much attention has been given to anticipated retirements of aging and uneconomic nuclear plants, and the adverse impact replacing these plants with fossil-fueled plants would have on carbon and greenhouse gas emissions. In addition to the 38 gigawatts of retired domestic nuclear capacity in the AEO97 case', the EIA anticipates 71 gigawatts of fossil generation will also retire by 2015 . Combined with new growth demand, a total of nearly 320 gigawatts of new generating capacity will be needed by 2015 , representing construction of nearly 1100 gasfired generating plants, or over 50 plants per year in the U.S. alone. Considering sensitivities to carbon emissions, implications of deregulation, and costs and delays likely resulting from local opposition to new plant construction, life extension of existing nuclear plants could be most advantageous to assuring a stable and reliable electrical supply system. 
Current EIA projections do not include projections for impacts of shifting transportation to electrical power, hydrogen or other manufactured fuels. Electrical demand would increase dramatically if significant fractions of transportation energy use were tied to it. For example $e^{6}$, if only $20 \%$ of the estimate 180 million U.S. automobiles and light trucks were converted to electrolytically produced hydrogen fuel, annual domestic electrical demand would increase by over 400 billion $\mathrm{kWh}$, roughly $12 \%$ of the 1995 demand. Berry, et al. (1966) have shown that such vehicles can be operated competitively with today's vehicles using electricity obtained from the grid.

\section{An uncertain future}

The world's energy future is uncertain, but there are also disparities in the distributions of energy demand growth and resources. Growth is more rapid among the developing countries and East Asia, and demand growth distribution does not overlap energy resource distribution.

The world's fossil fuel resource base, outside of coal, is limited, and coupled with disparities in distribution cause global concern for energy sustainability and energy security. Economics, jobs, standards of living and birth rates are inexorably tied to the availability of affordable energy. Energy disparities therefore lead to economic disparities and potential for mass migration and regional conflict, making energy security and sustainability national and international security issues.

There is also great uncertainty surrounding the technologies and technology mix used to meet this demand. Alternative and renewable technologies are in the same romantic period of development that nuclear fission and fusion enjoyed in the 60s, space flight in the 70's, and other technologies. Projections, promises, and hopes for these and other technologies fell short as physical laws, limitations of materials and infrastructures, energy demand, and increasing public sensitivities failed to meet expectations. The reality of any energy technology development is that it takes far longer to reach its perceived goals than anticipated, and that commercial development is best planned based on a technology status closer to that achieved in demonstrations rather than that hoped for.

The impact of utility deregulation on both nuclear and renewable energy technologies is expected to slow the growth of these sources without some form of strong incentives. Wind power is projected by the EIA as the major nonhydro renewable resource likely through 2015. Even in regions with favorable sites, the EIA notes that in an uncertain (deregulated) power market, without incentives (such as a carbon tax or carbon emissions cap) wind power will likely be used primarily as a fuel-saver and its overall contribution limited. The cost of solar photovoltaic is expected to remain too high for use in centralized power stations, and solar PV will likely remain an affordable option primarily for remote power generating applications.

Finally, there is uncertainty about the world's resolve to effectively limit carbon and greenhouse emissions, especially in light of costs and impact on economic growth. In the U.S. alone, trends toward deregulation are moving towards lowest cost options, and are expected to result in ever greater reliance on fossil fuel generation. Without specific incentives for emissions-free generation, or emissions based taxes on energy generation and use, carbon emissions in the U.S. and most other nations will continue to rise.

All of these uncertainties, the global energy future, and state and readiness of technology make it imperative that we maintain a robust set of options for meeting our current and future energy demands in environmentally responsible ways, and nuclear power, as a proven resources, is one of these options. 


\section{BENEFITS AND RISKS OF NUCLEAR POWER}

Nuclear power is an important, and sometimes contentious, national issue because it has both risks and benefits, just as any other technology. Unlike some national issues, however, there are important risks that accrue in today's world if the nuclear power option is abandoned.

Some of the major benefits of nuclear power are:

- It is a significant, stable and independent domestic and international energy resource, offering needed diversity and flexibility against future uncertainties,

- It is safe and environmentally sound, emitting few pollutants and no carbon or other greenhouse gases,

- Nuclear power is an important source of U.S. high-technology exports, and foreign demand for such exports is increasing,

- Nuclear power maintains U.S. positions of technical leadership and influence in important international policy areas such as nonproliferation, safety and waste management.

There are, of course, risks associated with nuclear power:

- There are proliferation implications and risks with nuclear power internationally,

- Spent fuel and waste management are significant issues,

- Nuclear safety remains a significant issue,
- Nuclear power cost is currently too high relative to most alternatives.

Just as there are risks associated with nuclear power, there are risks associated with not exploiting nuclear power:

- Loss of international influence and technical leadership,

- Erosion of critical infrastructures necessary to effectively deal with significant nuclear issues, including $D \& D$, waste management, and safety,

- Impaired energy options and flexibility.

If the U.S. is going to seriously meet its international environmental commitments, support a growing economy, and ensure its own as well as others' energy security, it must find ways to enhance and support nuclear energy as a part of the U.S. energy portfolio. The significant energy security and environmental benefits of nuclear power will only be realized if the undesirable risks associated with nuclear power are reduced. These risks can be reduced by wellfocused research and development.

In light of major uncertainties in the world's energy outlook and markets, clear needs for facilities and expertise to deal with existing and future security, safety and environmental issues, and continuing international tensions in much of the world, the U.S. simply cannot afford to allow its nuclear influence, infrastructures or options to erode further. 


\section{THE ISSUES}

There are four major issues contributing to the risk of nuclear power: nuclear safety, waste and spent fuel management, nuclear proliferation and economics. Fortunately, the risks associated with each of these issues can be reduced through a combination of R\&D and technology implementation, policy and regulatory reform, and shifts in public perception. In the R\&D approach, there are roles that both government and industry can and should play. Government's role in energy R\&D is to prepare the country for probable funures and guard against improbable ones. In energy, this means ensuring that the technical bases for a wide variety of energy options are available to meet the upcoming . challenges of our future energy needs. Industry's role is to take these technical bases and convert the most appropriate and economic options into industrialized and commercialized systems.

The first three of the four issues are clearly unique to nuclear power, and can be addressed essentially independent of the alternatives. Economics, on the other hand, is not independent of the alternatives. The first two issues can be viewed as being substantially technical issues (albeit having significant social and political overtones), and are substantially amenable to technical solutions. Nuclear proliferation is inherently both a technical and socio-political issues, and technical solutions can have major impacts on the risk of proliferation. While the economics issue can be addressed and improved through technical innovation, the economics of nuclear power can never be entirely divorced from that of the alternatives.

In addition to these four issues that must be addressed if nuclear power is to have a significant place in the U.S. energy future, there are three challenges that must be met even if nuclear power is allowed to decline. The current trend in the U.S. is abandonment of nuclear power in the face of global growth, and this presents very difficult challenges for the U.S. internationally, and places critical nuclear infrastructures and expertise in serious jeopardy,
In this current trend, the U.S. is faced with three very difficult challenges:

- Influence: How does the U.S. best influence the rest of the world in critical nuclear issues such as nonproliferation, waste management, and nuclear safety?

- Infrastructure: How do we maintain sufficient expertise and infrastructure to deal with the enduring nuclear issues such as waste and safety, both domestically and internationally?

- Future Options: Can the U.S. truly afford to preclude the use of nuclear energy in a future with uncertain environmental and energy security issues?

These challenges will persist independent of the future of nuclear power in the U.S. Meeting these challenges will require both domestically and internationally focused efforts.

Domestically, significant continuing research is needed on safety, waste management, and spent fuel minimization, and real efforts are needed focused on infrastructure maintenance, including efforts focused on maintaining critical educational and research resources. As a nation, we cannot afford to let our technical leadership and influence in important international nuclear issues wane. Nuclear proliferation, and international nuclear safety are issues in which the U.S. is losing, or threatening to loose its influence in because of it's current policies and decline of its nuclear industry. Both the U.S. and the rest of the world have an enduring need to maintain vital infrastructures to deal with nuclear waste, ensure continued safe and reliably operation of all nuclear plants, and to deal with the legacy of nuclear weapons production. A well-developed nuclear $R \& D$ program is essentially for meeting these vital, enduring national interests.

\section{Nuclear Safety}

Safety contributes simultaneously to nuclear power's benefits and risks. Nuclear power is operationally as safe as, or safer than, most 
aiternatives (coal plant effluents cause cancer, dams have failed) the consequences of a serious accident are large and the risks perceived to be great. While most Americans today appear to accept nuciear power as sufficiently safe, they do see nuclear power as having significant risks and are unwilling to pay a premium for it. Thus, safety even among those supportive of nuclear power, safety is intimately tied to economics and remains an important issues. Certainly the events at Three Mile Island and Chernobyl have made safety an enduring international nuclear issue, with events now having global impacts. Continued R\&D into reactor safety has proven beneficial, as the Advanced Light Water Reactor program has demonstrated. However, continued improvements in the safety of both existing and evolutionary reactor systems, as well as development of reactor systems featuring even greater reliance on inherent safety (rather than technical safety) will be key to the continuation of nuclear power as a viable energy alternative.

\section{Waste Management}

Waste Management, particularly that of spent fuel is one of the more contentious concerns the U.S. public has regarding continued use of nuclear energy. The Federal government is having difficulty meeting its statutory responsibility to manage the spent fuel from the nation's commercial nuclear power plants, leading to frustration on the part of utilities, electricity customers, and state leaders.

Although reasonable, sound technical solutions to this issue are essentially on-hand today, minority demands for non-attainable repository standards make this substantially a political and policy issue. Even so, there are technology avenues that can result in reduced waste and spent fuel accumulation, and continued $R \& D$ in this area can have important impacts.

\section{Nuclear Nonproliferation}

Nuclear proliferation is one of the risks associated with nuclear power. Reducing the risk of proliferation is and will remain an important worldwide goal, and it is the basis of much of the U.S. international nuclear dialogue and diplomacy. Two issues underlie proliferation risk: the illegal or clandestine use of declared facilities and/or materials, and theft of weapons-useable materials. Safeguards are an effective deterrent against diversion and misuse, and the major proliferation risk associated with commercial nuclear activities is plutonium trade and transport associated with plutonium recycle and MOX utilization, exacerbated by the growing stocks of separated plutonium due to the imbalance between separation and utilization. Large commercial reprocessing activities are in place in Europe. Russia, Japan and China have commercial reprocessing facilities under construction or planned. Other countries are likely to pursue reprocessing, both as a mechanism for extending energy resources and for waste management. Research into new fuel cycles for reduced spent fuel accumulation and reduced plutonium buildup, as well as research into new processes for proliferationresistant waste isolation could have substantial favorable impact on the proliferation resistance of this new generating capacity.

\section{Economics}

Economics of nuclear power in a changing domestic energy market is an increasingly important issue. Deregulation, with its attendant focus on lowest short-term generating costs, is disadvantageous to capital-intensive installations such as nuclear plants (and also to large coalfired plants as weil). Long construction times increases both cost and financial risk of nuclear projects, and although recent regulatory reforms have addressed this issue, more is needed.

Many of nuclear power's environmental costs have been internalized, through assessments to pay for spent fuel disposition. Currently, fossil environmental costs have not been intemalized. The cost of stabilizing U.S. carbon emissions at 1990 levels by the year 2010 has been estimated to require a carbon tax equivalent to somewhere between $\$ 10$ and $\$ 130$ per ton of carbon', and another study suggests that carbon emissions avoided might be valued at $\$ 50 /$ ton $^{2}$. Using this later value, and a value of $0.26 \mathrm{MtC} / \mathrm{TWh}$ for fossil fuel electrical generation suggests these cost might be equivalent to some 1.3 cents/kWh. Imposition of such an assessment (similar to that imposed on nuclear for spent fuel management) on fossil fuel generation would make both renewables and nuclear more attractive. 


\section{REQUIREMENTS FOR A NUCLEAR FUTURE}

Even though nuclear power has obvious and substantial advantages as an effective tool for managing carbon and greenhouse gas emissions while meeting energy demands, its economic costs are too high fòr substantial near-term growth in the U.S. For the longer term, the unique nature of nuclear power risks, its longlived radioactive waste, safety, and proliferation make a fundamental difference in the way these risks are perceived and evaluated. Ultimately, the future of nuclear power depends on our ability to continue to reduce the risks of nuclear power, both relative to the alternatives, and to absolute levels palatable to the general public.

One of the perceived differences between nuclear power and its alternatives may be that nuclear events are seen as having direct, global impacts, whereas events at conventional power plants are viewed as local. In terms of risk, the public therefore tends to treat nuclear risks as aggregated. This has significant implications for the future of nuclear power.

Consider the implications for reactor safety. Current reactors are designed to a goal of less than one chance of a serious accident in a million reactor-years. The current U.S. reactor fleet of some 100 reactors therefore represents a risk of a serious accident of roughly one in ten thousand years. The general public appears to accept this level of risk, as it is not clamoring for abandoning existing plants, but neither is it tolerant of new nuclear construction. Thus, we might take this level of risk to represent a limit for public acceptability of nuclear risks. Therefore, for an increase in the number of reactors in the U.S. to be publicly acceptable, safety standards, designs and practices themselves may require improvements to maintain this limit on aggregated risks.

Indeed, such an approach is neither unreasonably nor unprecedented. Even though our automotive travel increases, the U.S. public continues to demand, and receives, improvements in safety as measured in per-mile risks, thus maintaining control of overall aggregated automotive risks.
Engineered approaches to nuclear safety (and other risk reduction) may be reaching a point of diminishing returns, both technically and in the public's perception. Both the Three-Mile Island and Chernobyl events happened substantially because of operator errors, and technical complexity is perceived to have contributed to these errors. The public sees the systems as too complex even for the operators to understand, and is wary of additional reliance on technological fixes. Efforts to develop "passively safe" systems is a step in the right direction, and one that should be extended to the other elements of the fuel cycle.

Similar mechanisms may play in the perception of other nuclear risks, such as the risks of waste and spent fuel management. If we assume the perceived risks of these issues are similarly aggregated, then future growth of nuclear power is perceived as increasing these risks unless the risk probabilities are also proportionately reduced. The current U.S. philosophy of direct disposal contributes to the aggregation of risk. Waste segregation, coupled with actinide burning have the potential for reducing or eliminating the bulk of the long-lived radionuclides from the waste stream and reducing repository performance requirements Variations on these systems offer claims for further reduction in reductions in both high-level waste activity and volumes. Such simultaneous reductions in waste activity, volume and lifetime may be necessary for real future growth in nuclear power.

This view of risk presents several significant challenges for the future of nuclear power. Continuing evolutionary improvements in safety, waste management and other issues appear sufficient to maintain the existing nuclear fleet and, given favorable economics, to perhaps support incremental increases in installed nuclear capacity. However, reemergence of nuclear power as a viable, growing energy option for the future may require new approaches to nuclear fission, including a thorough reassessment of the entire nuclear fuel cycle. 
Significant growth in domestic nuclear power is unlikely in the near-term, and maintenance of a viable nuclear option for the future, even assuming that the costs and risks are maintained to acceptable levels, will depend on how the U.S. nuclear community, its infrastructures, expertise and industry, weather the current interregnum. There is no current U.S. market for new nuclear generating capacity, and "optimistic" scenarios suggesting that the current nuclear share of the market be maintained (at roughly $20 \%$ of U.S. generating capacity) translates to only one or two $1300 \mathrm{MWe}$ unit each year (with a current installed capacity of 100 Gwe and a projected electrical growth rate of some $1.5 \% / y e a r$ as suggested by the EIA reference case, and including replacements for retiring units.) Even this domestic market is likely insufficient to maintain effective U.S. nuclear infrastructures and industry.

Thus, maintaining a viable domestic nuclear option for the future is intimately tied to the global nuclear market and an effective U.S. presence in that market.

Maintaining the U.S. presence in the international nuclear markets is itself a challenge, with serious competition from the French and Japanese, and a growing presence from others including Canada and Korea. This challenge is intensified by the coupling between U.S. policy and diplomatic concerns with international nuclear trade, as exemplified in the ongoing U.S.-Chinese nuclear trade negotiations.

Differences between U.S. nuclear policies and those of potential customers is also often problematic. An example is the U.S. position on reprocessing which is seen by some as a deterrent to reliance on U.S. technologies and systems where potential customers view reprocessing as an important option for waste and resource management. Progress is needed in both technological and institutional approaches toward reducing the risks underlying such U.S. positions. Technologically, development of fueis for extended burnup may help reduce waste generation and resource utilization, reducing the imperative for reprocessing. Development of better reprocessing technologies, with enhanced proliferation resistance could make reprocessing better acceptable. Institutionally, better international control of sensitive fuel cycle processes and facilities, through enhanced oversight, regionalization, or bi- or multi-lateral control could be particularly effective.

The market for nuclear power in the less developed countries is potentially large. However the ability of nuclear power to penetrate these markets will be limited by several of the issues already discussed, including cost and proliferation risk, as well as some unique to the less developed countries, such as lack of supporting infrastructures and expertise, and limited capacity to absorb current large capacity plants. The ability of nuclear power to play a significant role in these countries will depend, in part, on the availability of nuclear systems capable of overcoming these limitations. Less expensive, smaller systems, relying on passive safety designs, and featuring enhanced proliferation resistance (perhaps by avoiding onsite refueling through use of lifetime cores) could make nuclear power an attractive option for simultaneously meeting energy demands and managing greenhouse gas emissions in many less developed countries, especially those deficient in indigenous energy resources.

Maintaining a U.S. presence in the international nuclear market, and influence in important international nuclear issues, particularly among the developing countries, also means becoming responsive to that market and the needs of the other countries. International dialogue and cooperation is essential for understanding the issues, capabilities and limitations of nuclear power from the perspectives of the other countries. Technical and institutional solutions to significant nuclear concerns that are effective in the U.S. or other industrial countries may be inappropriate for application in the less developed countries. 


\section{PROSPECTS FOR A NUCLEAR FUTURE}

Even if we successfully maintain the nuclear power option, by maintaining our infrastructures, advancing our technologies, and reducing the risks of nuclear power, we must ask the question "what are the prospects for nuclear power in America's and the world's energy future?" Alternatively, this might be phrased as "what other conditions are needed to support a resurgence of nuclear power in the U.S. ${ }^{m}$, and "under what conditions might the U.S. become a more willing supporter of an expansion of nuclear power globally?"

Clearly, one issue that the nuclear community cannot solve on its own is that of economics. Even assuming that technology innovation, and regulatory reform are effective at minimizing costs and economic risk, streamlining construction schedules, and solving siting and licensing uncertainties, nuclear power will likely remain a more capital-intensive energy form than its primary competition, namely coal and natural gas. As we are seeing today, utility deregulation appears to be developing in a way to value short-term economics, making all forms of capital-intensive electrical generation less attractive. Thus, greater acceptance of nuclear power will remain limited until greater emphasis on the environmental costs of fossil-fuel generation, such as implementation of carbon taxes and/or incentives for carbon-free generation, becomes accepted practice.

Nuclear safety, even with continued improvements in safety design and greater emphasis on inherent safety, will continue to remain a significant issue and challenge. Classically, both industry and government has responded to this challenge through both technology improvements and attempts at public education. Even though the former has been, and will continue to be, effective, the latter has proved difficult. One approach that may prove an effective tool in improving the public perception of nuclear safety is to listen to, rather than educate, the public. One theme that has been consistent and growing in the public response to nuclear safety issues is the public distrust of technical solutions to safety and a growing demand for better reliance on inherent solutions. The current reactor development trends in this direction must continue and be shown effective.

Waste and spent fuel management must be demonstrated as having both technical and institutional solutions. Ultimately, resource management will become important for nuclear power, and reprocessing, as a mechanism for management of both wastes and resources may need to be revisited.

International growth of nuclear power will result in continued concerns over the important issues of safety, proliferation and waste management. International solutions to these issues will become increasingly important to all these issues, both as direct solutions to the immediate issues, as well as mechanisms for reducing potential for conflict. For example, waste management is often treated as a national, not international issue. But as nuclear power expands globally, waste transportation through international trade routes, and siting of waste facilities become sources for international tensions requiring international solutions. 
'Energy scenarios encompass high and low ranges and are from: World Energy Council (1993) for 2020 (three cases - high growth, reference, ecologically driven); Holdren (1993) for 2010, 2050 and 2090; Starr, et al. (1992) for 2060; Hafele (1989) for 2030; and IIASA (1981) for 22030. The World Bank estimates (1994) a population of about 11 billion in 2100 . Low energy estimates assume, among others, continuous energy efficiency improvements on the order of 50 percent by 2100 .

${ }^{2}$ U.S. Energy Information Agency, 1997

${ }^{3}$ Current discussions about life extensions could reduce or delay the projected decline in U.S. nuclear capacity and reduce the need for replacement capacity.

4 International Energy Outlook, U.S. Energy Information Administration, 1997. The EIA high-growth case projects nuclear power generation to increase from the 1995 capacity of $344 \mathrm{Gwe}$ to nearly $450 \mathrm{Gwe}$ by 2015 . This highgrowth case projects only a small decline in domestic U.S. nuclear capacity (from 100 to 95 Gwe) over this period, but a substantial growth in nuclear capacity in essentially all other parts of the word: nuclear power in the rest of the industrialized countries grows from 178 to 212 Gwe; Eastem Europe and FSU from 46 to 66 Gwe; the developing countries from 21 to 77 Gwe.

'Annual Energy Outlook, U.S. Energy Information Administration, 1997

'Gene D. Berry, et al., "Hydrogen as a Future Transportation Fuel", Energy, Vol 21, \#4, pp 289-303, 1996

${ }^{7}$ Gaskins \& Weyant, 1993 as cited in "Technology opportunities to reduce U.S. greenhouse gas emissions", draft Sept 8 1997, p $1-5$

'Interlaboratory Working Group, 1997 as cited in "Technology opportunities to reduce U.S. greenhouse gas emissions", draft Sept 8 1997, p $1-5$ 


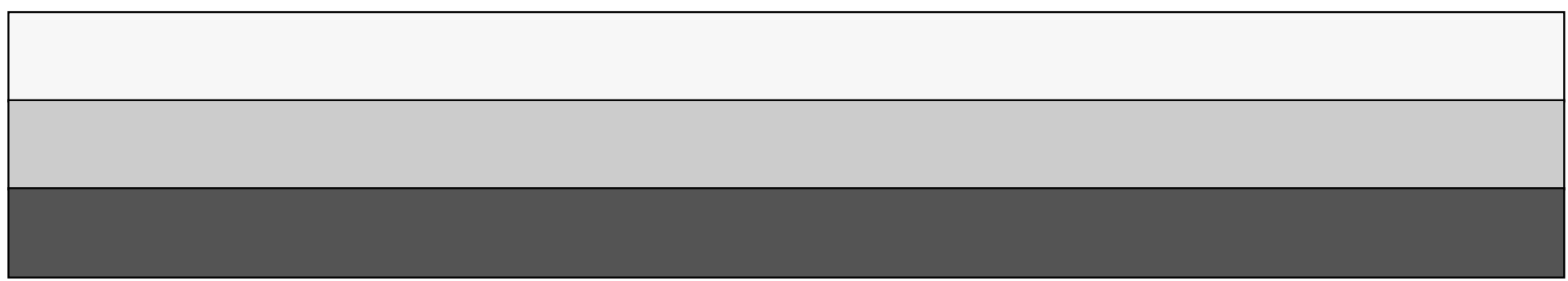

